Authors’ post-print version.

Leist, A. K., Novella, R., \& Olivera, J. (2018) The role of nutrition and literacy on the cognitive functioning of elderly poor individuals. Journal of Aging \& Social Policy, online 12 July 2018. doi: 10.1080/08959420.2018.1485390.

\title{
The Role of Nutrition and Literacy on the Cognitive Functioning of Elderly Poor Individuals
}

\author{
Anja K. Leist \\ University of Luxembourg, Institute for Research on Socio-Economic Inequality (IRSEI) \\ 11, porte des Sciences. L-4366 Belval, Luxembourg. anja.leist@uni.lu \\ Rafael Novella \\ Inter-American Development Bank (IDB) \\ 1300 New York Avenue, N.W. Washington, D.C. 20577, USA. rnovella@iadb.com \\ Javier Olivera $(\bowtie)$ \\ Luxembourg Institute of Socio-Economic Research (LISER) \& Pontificia Universidad Catolica del Peru \\ 11, Porte des Sciences, L-4366 Belval, Luxembourg. javier.olivera@liser.lu
}

\begin{abstract}
Maintaining cognitive function is a prerequisite of living independently, which is a highly valued component in older individuals' wellbeing. In this paper we assess the role of early-life and later-life nutritional status, education and literacy on the cognitive functioning of older adults living in poverty in Peru. We exploit the baseline sample of the Peruvian noncontributory pension program Pension 65 and find that current nutritional status and literacy are strongly associated with cognitive functioning for poor older adults. In a context of rising popularity of non-contributory pension programs around the world, our study intends to contribute to the discussion of designing accompanying measures to the pension transfer, such as adult literacy programs and monitoring of adequate nutrition of older adults.
\end{abstract}


Keywords: Cognitive function; old age; poverty; nutritional status; non-contributory pensions; arm span; Mini Nutritional Assessment; Peru 


\section{INTRODUCTION}

During the last years, several low and middle-income countries have implemented noncontributory pension programs as a way to fight poverty in old age. In general, these programs transfer small pensions (means tested or universal) to older adults who do not have a pension from the contributory pension system. The increasing popularity of these programs represents an important shift in the provision of social protection for old age. For example, many Latin American countries have implemented these programs as a way to rapidly expand old age protection in economies with large informal labor markets where the coverage of traditional pension systems is low ${ }^{1}$. These programs can be costly (Aguila et al. 2016), but many positive outcomes have been found on the wellbeing of older people: health (Aguila, Kapteyn \& Smith 2015; Galiani, Gertler \& Bando 2016), social and family support network (Case \& Menendez 2007; Edmonds, Mammen \& Miller 2005).

Without denying the importance of having a secure stream of income in old age, there are other aspects of the individual's wellbeing that will not necessarily improve with a small cash transfer. For example, keeping a good cognitive functioning in old age is crucial for the autonomy of older individuals, which is a highly valued dimension in their wellbeing. Although the decline of cognitive functioning is part of the ageing process, there are some protective measures that can help to retard this decline. Some of these measures could eventually be considered in the design of accompanying benefits and interventions to the pension transfer. In this study, we use a representative sample of older adults living in poverty in Peru and identify a significant role of nutritional status and literacy on the cognitive functioning of older adults. Therefore, our study intends to contribute to the discussion about designing complementary benefits to non-contributory pensions, such as adult literacy and nutritional programs.

Intervention programs designed to improve literacy and nutritional status have shown to be effective in maintaining cognitive health in late life. Indeed, while increasing literacy in 
children and adults is a goal in itself and supported by the Sustainable Development Goals agenda for 2030 (Hanemann 2015), illiteracy has additional severe economic, social, and wellbeing consequences in particular for older adults (Roman 2004). Additional benefits of literacy for maintaining cognitive health can be expected: Illiteracy is supposed to contribute substantially to the development of dementia in both developing and developed countries, with a magnitude, for instance, in South Korea estimated around 16 \% (Suh et al. 2016). Regarding adult literacy programs in developing countries, (Abadzi 2003) discusses the characteristics shared by successful interventions on increasing adult individuals' cognitive skills. The author shows that interventions combining inputs from neuropsychology (e.g., Neuroalfa literacy method, REFLECT methodology) with an adequate environment for learning (in terms of, courses duration, classroom conditions, materials, teaching preparation, among others) are particularly effective on improving adult individuals' cognitive skills, such as memory, attention, verbal skills and hypothesis formation. However, there is little evidence available on the possibilities of improving literacy in older adults and the associated possible benefits for older-age cognitive outcomes. Our study intends to provide observational evidence towards testing the possible benefits of literacy programs on older-age cognitive outcomes.

Regarding nutritional interventions, (Hughes \& Ganguli 2009) show evidence of different nutritional interventions positively affecting cognitive functioning in old age. Their paper discusses empirical studies where different exposures to micronutrients (e.g., polyphenols and antioxidants), macronutrients (e.g., fat, protein) and dietary patterns (e.g., the Mediterranean diet) affect cognitive health. Similarly, (Van Dyk \& Sano 2007) review different interventions and control trials seeking to predict the effects of nutrition and different diets on cognition in older people. They mention that some types of diets (e.g. whole grains, natural sugar and fish) may protect against cognitive decline. Interventions related to nutrition manipulation are generally carried out in institutions such as old-age homes and not in large- 
scale programs such as the non-contributory pension schemes. The "Nutrition Transfer for Senior Adults” program (Pension Alimentaria para Adultos Mayores) was implemented in Mexico City in 2001 to provide cash in a debit card for older residents of poor areas (aged 70 or more) to buy food in associated grocery shops. However, the purchase of other items was also permitted, and the program became a more standard non-contributory pension scheme for older people of Mexico City (Juarez 2009).

It has been found that early childhood experiences like poverty and deprivation are associated with lower cognitive function at older ages (Case \& Paxson 2008; Guven \& Lee 2013) and that, in general, cognitive impairment and dementia may have their origins in early life environment (Glymour et al. 2011). Particularly, inadequate nutrition may hinder the building up of cognitive reserve at early ages and increase the risk of old-age cognitive impairment and dementia (Melrose et al. 2015; Whalley, Dick \& McNeill 2006). A recent study showed exposure to famine at early ages increased cognitive aging (Kang et al. 2017). Proxies for early-life nutritional status such as height, arm span, limb length and other anthropometric measures have been shown to be associated with cognitive function at older ages, with arm span (available in our data) being a valid and reliable proxy for other anthropometric measures as well as an adequate marker for childhood development and nutritional status (Huang et al. 2008; Jeong et al. 2005; Kim et al. 2003; Maurer 2010; Patel et al. 2011). Due to potentially different early-life conditions of women and men with regard to length of schooling and nutrition in the parental household, one may assume gender differences in the link between nutrition, literacy, and cognitive function. Similarly, later-life nutritional status has been shown to be associated with cognitive impairments (Suominen et al. 2005). Our dataset includes the Mini Nutritional Assessment (MNA), which is an instrument utilized to evaluate the risks of under-nutrition and malnutrition of older individuals (Guigoz 2006; Harris \& Haboubi 2005; Vellas et al. 1999). 
The challenges of aging populations in developing countries require more knowledge about successful aging (García-Lara et al. 2016). One substantial difference between developed and developing countries is the level of schooling of today's older cohorts. Education is a powerful and independent indicator of cognitive reserve and strongly associated with later-life cognitive function (Stern 2002). The influence of education to modify the relationship between nutritional status and cognitive function has rarely been investigated in samples of loweducated individuals. In our sample only $21 \%$ of individuals have completed primary education or more, and the rate of illiteracy measured with a reading test is $27 \%$. This setting allows to estimate to what extent early- and late-life nutritional status and cognitive function are directly associated at older ages, both with and without the influence of education and literacy. We argue that education is protective of later cognitive function and that literacy may drive this relationship.

\section{BACKGROUND}

Peru’s economy has substantially improved in the last decade. For instance, the national poverty rate (measured with poverty lines for household consumption per capita) decreased from $58.7 \%$ in 2004 to $21.8 \%$ in 2015 . Educational attainment has also improved in the same period: for individuals aged 60 or more, it increased in one year; and younger individuals has, on average, two more years of education than the first group. However, large inequalities still persist in the country. For instance, the poverty rate in 2015 in rural areas is three times the one in urban areas (45\% versus $15 \%$, respectively); and, education attainment in rural areas, on average, is three years lower than in urban areas. Looking at the educational level achieved by different age groups in the Peru's National Household Survey (ENAHO) of 2012, which is the year of collection of our sample, we observe some acute differences between individuals living in rural and urban areas. In rural areas only 33\%, 21\%, $16 \%$ and $12 \%$ of individuals aged 60 64, 65-69, 70-74 and 75-79, respectively, have at least completed primary education, while 
these percentages are $75 \%, 66 \%, 60 \%$ and $55 \%$ in the urban areas. Women living in rural areas are the ones with the lowest educational level. Only 23\%, 17\%, 9\% and 5\% of women aged 60-64, 65-69, 70-74 and 75-79, respectively, have at least completed primary education, while these percentages are $48 \%, 34 \%, 27 \%$ and $21 \%$ for men in rural areas.

In a study utilizing the ENAHO 2011, Olivera \& Clausen (2014) describe that about $74 \%$ of the total elderly population (aged 65 and over) do not receive any type of pension, and that this percentage is $99 \%$ and $94 \%$ among the elderly individuals who are considered extreme poor and non-extreme poor, respectively. This can explain why a large share of the old population keep working at advanced ages. About $50 \%$ and $90 \%$ of the population aged 65 or more still work in urban and rural areas, respectively. The low levels of pension coverage are explained by the large informal market operating in Peru in which social security contributions are not compulsory. The non-contributory pension program Pension 65, which gives a bimonthly transfer of 250 Soles (about US\$ 77) to eligible individuals, was introduced at the end of 2011 as a new instrument to fight poverty in old age. As today, this program has half a million recipients and costs each year about $0.12 \%$ of GDP. To be eligible for this program, individuals must be aged at least 65 , not being covered by social security and live in a household officially classified as extremely poor. As mentioned in the introduction, we use the sample of the baseline survey conducted at the end of 2012, which is intended to be used to evaluate the program.

It is worth mentioning that there are ethnic differences in the access to education and other services as indigenous groups have systematically suffered from social exclusion, particularly groups living in the highlands of Peru. Due to the eligibility criteria of living in extreme poverty, most of the recipients of Pension 65 are located in rural areas and are indigenous. In our sample $62 \%$ of the individuals live in rural areas and the rest in urban areas; and $70 \%$ of the individuals have an indigenous mother tongue. Indeed, our study is also 
interesting because we are looking at the relationship between cognition, nutrition and education in a population of individuals who have experienced cumulative deprivations in many dimensions. For example, Dell (2010) illustrates the long-term effects of mandatory mining work in Peru's highlands on the current health of indigenous people. Other hardships suffered by the generation of our sample are that the illiterate were not allowed to vote in political elections before 1980, and that the Agrarian Reform Bill (Reforma Agraria) was only implemented during the early 1970s. This major redistribution of land represented the end of the Haciendas system, in which an impoverished labor force of peasants was attached to rural states.

\section{METHOD}

\section{Sample and Procedures}

The data come from the Survey of Health and Wellbeing of the Elderly (Encuesta de Salud y Bienestar del Adulto Mayor, ESBAM). This survey was commissioned by Peru's Ministry of Development and Social Inclusion, financed by the Ministry of Economy and Finance and collected by the National Institute of Statistics of Peru (INEI) with the aim to serve as baseline of the non-contributory pension program Pension 65. The data include information on socio-economic variables, health, nutrition, cognitive functioning, anthropometrical measures, and biomarkers.

The sample is representative of households with at least one member aged 65-80 and whose socio-economic classification score lies in the vicinity of the official threshold to determinate extreme poverty. The data was gathered in 12 (out of 24) departments of Peru. In Peru, households receive an official socio-economic score in order to determine eligibility for social assistance. This is the so-called targeting score SISFOH (Sistema de Focalizacion de Hogares) based on the household's material conditions, assets, incomes, household size and 
labor status and schooling of their members. The households can be classified as non-poor, non-extreme poor and extreme poor by comparing their SISFOH score with official regional poverty thresholds ${ }^{2}$. The program Pension 65 requires that recipients must live in a household classified as extreme poor. The original sample consists of 4,151 individuals, but after dropping observations with missing values in our covariates of interest, the final sample is composed of 3,910 individuals.

\section{Measures}

Cognitive function. Cognitive function is assessed with a reduced version of the minimental state examination (MMSE) (Folstein, Folstein \& McHugh 1975), which is similar to that of the Survey on Health and Well-being of Elders (SABE) conducted in capital cities of Latin America and the Caribbean in 1999-2000 (Pelaez 2005). This instrument was designed to take into account low literacy levels predominant in Latin American older adults (Maurer 2010). The MMSE score of SABE ranges from 0 to 19 points, but the score available in ESBAM ranges from 0 to 14 points because this does not include the backward counting test. In ESBAM, five components of cognitive functioning are assessed: orientation assesses correct answers on day of month, month, year and day of week, immediate recall is assessed by asking the respondent to repeat three words that were read out loud. Delayed recall is assessed by asking to repeat the same three words after a certain delay, each correct word received one point. Immediate and delayed recall are summarized to an episodic memory score (0 to 6 points). The respondent then had to follow three actions: "I will give a piece of paper. Take this with your right hand, bend in half with both hands and place on your legs". Each correct action receives one point. Drawing is assessed by the request to draw two intersected circles, provided that the circles do not cross more than half. Orientation, action, and drawing are summarized to a mental intactness score (0 to 8 points). The distinction between episodic memory and mental intactness is similar to the one done by (Lei et al. 2014) with Chinese data. 
Education. Given the low level of education attainment in the sample, education is measured with dummy variables indicating the levels 'no education', 'uncompleted primary education' and 'primary education or more'. The number of years of education is also used in the analysis. In ESBAM, individuals who reported uncompleted primary education, preprimary education or no education as their highest level of schooling were also asked whether they are illiterate (“do you know how to write and read?”). Then, the individual was requested to read a paragraph of 20 words to validate the self-selection answers. A dummy variable illiterate takes value 1 if the reading test failed and zero otherwise. The reading test was not collected for 108 individuals, so that illiterate is based on the self-report of these individuals.

Nutritional status. The nutritional status experienced in early life is assessed by arm span, which is an indicator similar to leg length (Jeong et al. 2005) and more reliable than height measures which can be biased due to shrinkage in old age (Huang et al. 2013). Arm span has been found to be an effective surrogate measure for height and indicator for nutritional status in an Indian sample (Datta Banik, 2011). The actual nutritional status in old age is assessed by an adapted version of the Mini Nutritional Assessment (MNA) (Guigoz 2006; Olivera \& Tournier 2016; Vellas et al. 1999) which is one of the best validated and most widely utilized screening for malnutrition (Morley, 2011). The MNA has also been used in the SABE study. The MNA is composed of items related to diet quality, mobility, disease history and anthropometrical measures. In our study, the maximum possible score of the adapted MNA is 22. Higher scores indicate better nutritional status.

Mental disorders. This is a self-reported variable computed from a list of 12 diseases. The variable takes value 1 if the individual indicated at least one of the following diseases: (1) depression, (2) stroke or brain hemorrhage, (3) diseases of the nervous system, Alzheimer, memory loss; and takes 0 otherwise. 
Smoking. This variable is constructed from a question that includes two parts: (1) "have you smoked cigarettes (tobacco) during the last 30 days?; and, (2) "Even if you have not smoked during the last 30 days, have you smoked before?”. The variable included in our analysis takes value 1 if an individual indicates he has smoked during the last 30 days or before, and 0 otherwise.

Socio-demographic variables. We include the following variables in the regressions: age and dummy variables for urban area of residence (rural is the reference value) and retired status (working is the reference value).

\section{Strategy of Data Analysis}

Regarding the method of analysis, we regress the score of cognitive functioning on socio-demographic, nutritional and education variables. The score of cognitive functioning ranges between 0 and 14 and its distribution tends to be left-skewed. By construction, the score suffers from "ceiling effects” and hence Tobit models are employed to take into account the right censoring of the dependent variable, as in (Maurer 2010). These models assume that the dependent variable is a latent dependent variable $Y^{*}$ censored at $\bar{Y}$, so that one can only observe this value if $Y^{*} \geq \bar{Y}$. The model formalization is the following:

$$
\begin{gathered}
Y^{*}=X \beta+\varepsilon, \quad \varepsilon \sim N(0, \sigma) \\
Y= \begin{cases}Y^{*} & \text { if } Y^{*}<\bar{Y} \\
\bar{Y} & \text { if } Y^{*} \geq \bar{Y}\end{cases}
\end{gathered}
$$

$Y^{*}$ is the latent cognitive functioning score, $\mathrm{X}$ are explanatory variables, $\beta$ are coefficients and $\varepsilon$ is the error term, which is assumed to be normally distributed. The models are estimated by maximum likelihood, and the standard errors are robust and clustered at the 
level of the department. Although no reported, the regressions include dummy variables for departments as a way to control for departmental unobserved effects. Moreover, to account for potential gender differences, all regressions are run separately for women and men. To account for heterogeneous effects of education at different levels of nutritional status, we include to the previous list of explanatory variables, interaction terms of education with arm span and Mini Nutritional Assessment. Finally, the models are run in a subsample of individuals who did not receive any formal schooling (but some were literate) as a way to uncover the impact of literacy and nutrition without any influence of formal education.

\section{RESULTS}

The descriptive statistics are reported in Table 1. The average age is 71 years for men and women. The average years of education is only 2.7 for the total sample, but there are some differences by gender. In average, men have 3.6 years of education and women have 1.6 years. In addition, women suffer more from illiteracy. About half of women are illiterate, while $11 \%$ of men are so. This translates in men having a better score of total cognitive functioning and mental intactness than women. There are not differences in the score of episodic memory. The average Mini Nutritional Assessment score is 13.58 points and there are statistically significant differences in favor of men. The differences of means by gender of all variables entering into the regressions are reported in the last column of Table 1. As anticipated, initial analyses suggested differential results patterns for men and women. For this reason, the analysis will be stratified by gender.

- TABLE 1 ABOUT HERE -

- TABLE 2 ABOUT HERE -

The main regression results of the Tobit models are reported in Table 2. Mental disorders are negatively associated with each component of cognition in both genders, but 
smoking is not significant in any case. As a check, we ran the regressions of Table 2 with three dummy variables for each of the three diseases embedded in the variable mental disorders. There is not a statistically significant relationship between cognition and depression, but there is a statistically significant relationship between cognition and the other two diseases. We do not find a significant statistical relation between smoking and cognition. As a check, we also run the regressions of Table 2 with an alternative construction for smoking indicating lifetime smoking (this variable takes value 1 if an individual has smoked before the last 30 days, and 0 otherwise) and neither reveals a significant relationship with cognition.

The MNA score is positively and sizably associated with each component of cognition for both men and women. The association of MNA with total cognition is larger among women than among men. For instance, an extra point in the MNA score (having a better nutritional status) is associated with an increase of total cognition in the same magnitude as if men were one year younger and women two years younger. Education is also an important and statistically significant predictor for total cognition and its components. For instance, compared to no education, having uncompleted primary education is associated with an increase of total cognition by 0.77 and 1.47 points in the cases of men and women, respectively. Moreover, having completed primary education or more is associated with an increase of total cognition by 1.47 and 2.23 points for men and women, respectively. Arm span is significantly associated with total cognition and mental intactness. In the case of regressions for total cognition (Tables 2's columns 3 and 6) having 10 extra centimeters of arm span is similar to being about 1.7 years younger both for men and women. Our results show that the association of education and current nutritional status (measured with MNA) with later-life cognitive functioning is more important for women than men, and that the contribution of nutritional status experienced in childhood (measured with arm span) on explaining later-life cognition is similar between men and women. 


\section{- TABLE 3 ABOUT HERE -}

Table 3 shows the results of models employing interactions of education with nutritional status. In general, with the exception of education and arm span for men's episodic memory, we do not observe presence of heterogeneous effects of education and nutritional status. Results do not qualitatively change when the variable education is measured in terms of years of schooling instead of educational levels.

Table 4 shows the results of applying the same analysis to a subsample of individuals who did not receive any formal schooling (189 men and 802 women). Interestingly, in this sample there are 87 men and 104 women who are literate according to the reading test, which reflects that they might have learnt to read through informal channels or at adult literacy programs. Associations between predictors and cognitive functioning are similar to previous models but in some cases fail to reach significance, potentially due to the small sample size. Arm span is positively associated with episodic memory for men, and it is positively associated with mental intactness and total cognition for women. The MNA score is positively associated with cognition for both genders (for men in mental intactness, for women in all components). Lastly, being illiterate is significantly negatively associated with cognitive functioning in both genders, with the only exception of mental intactness for women, though the p-value is marginally larger than the $10 \%$ threshold $(p$-value $=0.12)$.

\section{- TABLE 4 ABOUT HERE -}

We know that nutrition and cognition are positively associated with economic status, and therefore not including a variable controlling for economic status may lead to an omitted variable problem. However, we should keep in mind that our sample is composed of very poor older adults whose living conditions (captured by the SISFOH score) are very similar and located in the vicinity of the official threshold to determine extreme poverty. If our sample 
were a population-wide sample, not accounting for the economic status may be a problem. In any case, we have assessed how our results can change if we add into the regressions of table 2 and 4 a variable indicating the economic status of the individual. We do not have access to the official SISFOH score but at least we know which individuals were assigned into control (a score just above the official threshold) and treatment (a score just below the official threshold) groups for a posterior impact evaluation (see endnote 2). As the SISFOH is an indicator of the economic status of the individual's household, we consider this is a good proxy for the economic status of the individual. The inclusion of a dummy variable indicating the treatment or control assignment does not change our results, nor the statistical significance of the coefficients of interest. In addition, the coefficient of this dummy is not statistically significant in the regressions of Table 2 (full sample of analysis), and is significant in the model regressions of mental intactness and total cognition for men in Table 4 (the subsample of uneducated individuals).

\section{DISCUSSION}

\section{Explanation of Findings}

Maintaining cognitive functioning is vital for autonomous and well-functioning old age. While to date no interventions exist to reverse cognitive decline, evidence on life-course factors able to delay cognitive decline and impairment is urgently needed (Leshner et al. 2017). This study tested the associations between early-life (arm span) and later-life (MNA) nutritional status and cognitive functioning, suggesting -in line with previous studies- that improving nutrition could improve cognitive outcomes in developing countries. Further, uncompleted and completed primary education were positively associated with cognitive function, suggesting - although our research design does not allow causal conclusions - that

even small 'doses' of schooling are vital for maintaining cognitive reserve up to higher ages. A reverse association of children with higher initial cognitive skills being selected or able to 
receive longer schooling is also possible. Men with less favorable early-life nutritional status and low education show particularly poor cognitive function. These observational findings should justify further research with rigorous causal tests, and the elaboration if noncontributory pensions programs should be flanked with programs to improve nutrition and literacy at older ages.

We find gender differences in the interaction between arm span and having at least primary education; this interaction is only significant in men's episodic memory. This suggests that, for men, education seems to 'compensate' early nutritional deficits and decreases in importance with better early-life nutritional status. We suggest biological and gender normbased explanations for why this interaction of nutrition and education does not reach significance in women. Biologically driven gender differences could determine how well arm span reflects early-life nutritional status, or there could be gender differences in associations of nutritional status and cognition. Further, boys and girls may have systematically received nutrition of different quality during childhood. The higher number of uneducated women suggests that at least part of the gender differences are driven by selection into education in childhood. (Ilahi, 2001) finds gender differences in schooling and household chores of boys and girls in Peru, although we have little empirical evidence on the childhood conditions of our sample of older adults in Peru. The lack of significant interaction for mental intactness is likely to be due to ceiling effects, i.e., this measure not being sensitive enough to catch differences in more elevated cognitive functioning of educated men and women.

Identifying precedents of cognitive impairment and dementia in developing countries is vital as it is the leading cause for disability in developing countries (Sousa et al. 2009). Earlier research has found illiteracy to be an important contributor to dementia all over the world (Suh et al. 2016). Further, we find that malnutrition at early ages may put individuals, especially men with low education, at particular risk for cognitive impairment at older ages. This finding 
is aligned with the evidence that chronic malnutrition in infancy is associated with cognitive and behavioral deficits across the lifespan (Wachs 1995). Moreover, lower nutritional status in childhood, assessed as height-for-age, has been found to be associated with dementia and cognitive impairment at older ages, as well as with higher burden of infection net of socioeconomic variables, infection being an important possible determinant of later-life morbidity and mortality (Dowd, Zajacova \& Aiello 2009). This paper also replicates the importance of education, which has been found to be the main contributor to maintaining cognitive function up to old age (Lee et al. 2003; Meng \& D’Arcy 2012). Our paper adds that education may be particularly beneficial due to acquiring literacy. Being literate could be the main prerequisite for successfully completing education and further cognitively stimulating tasks across the life span like reading or using technological devices (depending on their availability).

As stated at the beginning of the paper, both nutritional status and literacy are dimensions that can be affected by tailored-designed interventions. Our paper, in line with previous studies in different contexts, points to the possibility of benefits of improving nutrition and literacy at older ages. Future research with rigorous study designs is needed to provide evidence if improvements in these dimensions are indeed able to improve older individuals' cognitive function. To preserve cognitive functioning and have more autonomous older adults, it is key that programs fomenting retirement, such as non-contributory pension programs, test potential of additional interventions to their design.

\section{Limitations}

We use a measure of cognitive functioning that is based on the MMSE, which is one of the most used and studied tests worldwide, and that is similar to the one collected in SABE for older adults in Latin America. Although there is an advantage in comparability, the use of a single measure of cognitive functioning imposes restrictions to analyze how our main variables 
of interest are associated to other measures (e.g., the Montreal Cognitive Assessment) or other relevant cognitive dimensions not included in MMSE (e.g. attention, speed of processing general information).

Arm span is only a crude indicator of early-life nutritional status, but it has been shown to be similarly valid as limb length. However, we cannot rule out that differences in arm span may have already been produced at the prenatal stage, as socioeconomic differences in childhood growth seem to be prenatally determined (Howe et al. 2012). It is also possible that individuals with shorter arm span did not receive equivalent schooling compared with men and women with greater arm span, as found in the Honolulu Asian Study for height (Abbott et al., 1998), leaving the question of causality of this association unresolved. We cannot rule out that this kind of selection may have biased our findings.

Geographical specificities of Peru include different altitudes of the respondent's residences. High altitudes result in blood anomalies and have been shown to be associated with compromised infant health (Wehby, Castilla \& Lopez-Camelo 2010). ESBAM does not contain information about district of birth, so that we cannot possibly rule out migration between highand low-altitude areas and the potential confounder of birth in a high-altitude area. It is necessary to keep in mind that due to harsh circumstances of older poor people living in Peru, a significant part of the birth cohorts under investigation have already died at age 65. Based on period life-tables of 1950-51 (Arriaga 1966), approximately 25\% of men and 32\% of women have been expected to survive until age 65 in the year the sample was collected. We cannot rule out that selective or gender-differential mortality has been producing these results. Lastly, we did not find any association between smoking and cognitive function, which may be due to selective mortality of smokers at younger ages.

Finally, we use a dichotomous measure of literacy available in this study (see (Hanemann 2015) for a continuous conceptualization of literacy of different proficiency 
levels), and find that literacy provides a distinctive advantage during the aging process to preserve cognitive functioning. Similar to the findings suggesting positive links between nutrition and cognitive functioning, we acknowledge however the lack of a study design enabling us to causally test if literacy and nutrition interventions improve cognitive outcomes at older ages. Nonetheless, the analysis of this observational cross-sectional study gives strong implications of potential mechanisms to improve cognitive functioning in older people in a developing country. Future research with rigorous study designs is necessary to provide more evidence about the benefits of literacy and nutritional interventions on old age cognition. We further cannot rule out a potentially reverse mechanism in that literacy could be associated with cognitive ability due to the fact that individuals with higher cognitive abilities are more likely to learn to read at earlier life stages, even without proper schooling. Further studies with longitudinal designs should explore these mechanisms in more detail.

\section{CONCLUSION}

We find that early-life and later-life nutritional statuses are significantly associated with cognitive function in old age, replicating the importance of adequate nutrition for cognitive functioning. Further, without any schooling, being literate is strongly positively associated with cognitive functioning, suggesting that literacy may drive associations of education and cognition. Nutritional status should be monitored in older adults deprived from socioeconomic resources in order to prevent cognitive impairment. Policies supporting adequate nutrition at all ages could help preserving cognitive levels of the older population, especially in less developed countries. Equally, policy measures implementing literacy programs for adults could have potentially important positive benefits for cognitive function up to older ages.

In a context of rising popularity of non-contributory pension programs around the world, this study sheds light on the importance of testing the benefits of additional interventions with the aims of keeping a good nutritional status in old age and improving literacy, ideally to 
preserve later-life cognitive functioning and maintain autonomy in older individuals. It could be the case that these non-contributory pension schemes can learn from conditional cash transfer programs and incorporate complementary components related with nutrition and literacy as a way to enhance the wellbeing of poor individuals at older ages. 


\section{NOTES}

1. In Latin America, about 17 countries and 19 million of individuals (32\% of the $60+$ population) receive a non-contributory pensions. This figure refers to the period 20122013 and is computed with data extracted on 22-12-2016 from http://www.pensionwatch.net/ and the United Nations’ World Population Prospects 2015 revision.

2. The data was gathered in 12 departments (out of 24), where the Ministry of Development and Social Inclusion (MIDIS) had already completed the census of socioeconomic variables intended to update its household targeting score system (SISFOH) and where, according to administrative records, 70 percent of Pension 65 beneficiaries lived. Households in the sample where randomly drawn from the total number of households with at least one adult between the ages of 65-80, eligible to Pension 65, and whose SISFOH score were 0.3 standard deviations above and below the SISFOH extreme poverty threshold. Households with a score above and below this threshold were classified as 'non extreme poor' and 'extreme poor', respectively, and therefore were assigned into control and treatment groups for a posterior impact evaluation. The sampling selection was probabilistic, independent in each department, stratified in rural/urban areas and carried out in two steps. In the first step, the primary sampling units (PSU) were census units in urban areas and villages in rural areas with at least four households living in poverty and with elderly members. The selection of PSU was made by probability proportional to size (PPS) according to the total number of households. In the second step, four households were randomly drawn from each PSU for interview and two for replacements. 


\section{REFERENCES}

Abadzi, H. (2003). Improving adult literacy outcomes: Lessons from cognitive research for developing countries: World Bank Publications.

Abbott, R. D., White, L. R., Ross, G. W., Petrovitch, H., Masaki, K. H., Snowdon, D. A., \& Curb, J. D. (1998). Height as a marker of childhood development and late-life cognitive function: The Honolulu-Asia Aging Study. Pediatrics, 102(3), 602-609. doi:10.1542/peds.102.3.602

Aguila, E., Kapteyn, A., \& Smith, J. P. (2015). Effects of income supplementation on health of the poor elderly: The case of Mexico. Proceedings of the National Academy of Sciences, 112(1), 70-75.

Aguila, E., Mejia, N., Perez-Arce, F., Ramirez, E., \& Rivera Illingworth, A. (2016). Costs of extending the non-contributory pension program for elderly: The Mexican case. Journal of aging \& social policy, 28(4), 325-343.

Arriaga, E. E. (1966). New abridged life tables for Peru: 1940, 1950-51, and 1961. Demography, 3(1), 218-237.

Case, A., \& Menendez, A. (2007). Does money empower the elderly? Evidence from the Agincourt demographic surveillance site, South Africa. Scandinavian journal of public health, 35(69 suppl), 157-164.

Case, A., \& Paxson, C. (2008). Height, health, and cognitive function at older ages. The American Economic Review, 98(2), 463-467.

Datta Banik, S. (2011). Arm span as a proxy measure for height and estimation of nutritional status: A study among Dhimals of Darjeeling in West Bengal India. Annals of human biology, 38(6), 728-735.

de Carvalho Filho, I. E. (2008). Old-age benefits and retirement decisions of rural elderly in Brazil. Journal of development economics, 86(1), 129-146.

Dowd, J. B., Zajacova, A., \& Aiello, A. (2009). Early origins of health disparities: burden of infection, health, and socioeconomic status in US children. Social Science \& Medicine, 68(4), 699-707.

Edmonds, E. V., Mammen, K., \& Miller, D. L. (2005). Rearranging the family? Income support and elderly living arrangements in a low-income country. Journal of Human Resources, 40(1), 186-207.

Folstein, M. F., Folstein, S. E., \& McHugh, P. R. (1975). "Mini-mental state”: a practical method for grading the cognitive state of patients for the clinician. Journal of psychiatric research, 12(3), 189-198.

Galiani, S., Gertler, P., \& Bando, R. (2016). Non-contributory pensions. Labour Economics, 38, 47-58.

García-Lara, J. M. A., Navarrete-Reyes, A. P., Medina-Méndez, R., Aguilar-Navarro, S. G., \& Ávila-Funes, J. A. (2016). Successful aging, a new challenge for developing countries: The Coyoacán Cohort. The journal of nutrition, health \& aging, 1-5. doi:10.1007/s12603-016-0728-8

Glymour, M. M., Kosheleva, A., Wadley, V. G., Weiss, C., \& Manly, J. J. (2011). Geographic distribution of dementia mortality: Elevated mortality rates for Black and White Americans by place of birth. Alzheimer Disease and Associated Disorders, 25(3), 196202.

Guigoz, Y. (2006). The Mini Nutritional Assessment (MNA $\left.{ }^{\circledR}\right)$ review of the literature-what does it tell us? Journal of Nutrition Health and Aging, 10(6), 466-487.

Guven, C., \& Lee, W. S. (2013). Height and cognitive function at older ages: is height a useful summary measure of early childhood experiences? Health economics, 22(2), 224-233. 
Hanemann, U. (2015). Lifelong literacy: Some trends and issues in conceptualising and operationalising literacy from a lifelong learning perspective. International Review of Education, 61(3), 295-326.

Harris, D., \& Haboubi, N. (2005). Malnutrition screening in the elderly population. Journal of the Royal Society of Medicine, 98(9), 411-414.

Howe, L. D., Tilling, K., Galobardes, B., Smith, G. D., Gunnell, D., \& Lawlor, D. A. (2012). Socioeconomic differences in childhood growth trajectories: at what age do height inequalities emerge? Journal of Epidemiology and Community Health, 66(2), 143-148.

Huang, T., Carlson, M., Fitzpatrick, A., Kuller, L., Fried, L., \& Zandi, P. (2008). Knee height and arm span: A reflection of early life environment and risk of dementia. Neurology, 70(19 Part 2), 1818-1826.

Huang, W., Lei, X., Ridder, G., Strauss, J., \& Zhao, Y. (2013). Health, height, height shrinkage, and SES at older ages: evidence from China. American Economic Journal: Applied Economics, 5(2), 86-121.

Hughes, T. F., \& Ganguli, M. (2009). Modifiable midlife risk factors for late-life cognitive impairment and dementia. Current psychiatry reviews, 5(2), 73-92.

Ilahi, N. (2001). Children's work and schooling: does gender matter? Evidence from the Peru LSMS.

Jeong, S. K., Kim, J. M., Kweon, S. S., Shin, M. H., Seo, M. W., \& Kim, Y. H. (2005). Does arm length indicate cognitive and functional reserve? International journal of geriatric psychiatry, 20(5), 406-412.

Juarez, L. (2009). Crowding out of private support to the elderly: Evidence from a demogrant in Mexico. Journal of Public Economics, 93(3), 454-463.

Juárez, L., \& Pfutze, T. (2015). The effects of a noncontributory pension program on labor force participation: The case of 70 y Más in Mexico. Economic Development and Cultural Change, 63(4), 685-713.

Kang, Y., Zhang, Y., Feng, Z., Liu, M., Li, Y., Yang, H., . . . Cheng, L. (2017). Nutritional deficiency in early life facilitates aging-associated cognitive decline. Current Alzheimer Research, 14(8), 841-849.

Kim, J., Stewart, R., Shin, I., \& Yoon, J. (2003). Limb length and dementia in an older Korean population. Journal of Neurology, Neurosurgery \& Psychiatry, 74(4), 427-432.

Lee, S., Kawachi, I., Berkman, L. F., \& Grodstein, F. (2003). Education, other socioeconomic indicators, and cognitive function. American journal of epidemiology, 157(8), 712-720. doi:10.1093/aje/kwg042

Lei, X., Smith, J. P., Sun, X., \& Zhao, Y. (2014). Gender differences in cognition in China and reasons for change over time: Evidence from CHARLS. The Journal of the Economics of Ageing, 4, 46-55.

Leshner, A. I., Landis, S., Stroud, C., \& Downey, A. (2017). Preventing cognitive decline and dementia: A way forward: National Academies Press.

Maurer, J. (2010). Height, education and later-life cognition in Latin America and the Caribbean. Economics \& Human Biology, 8(2), 168-176.

Melrose, R. J., Brewster, P., Marquine, M. J., MacKay-Brandt, A., Reed, B., Farias, S. T., \& Mungas, D. (2015). Early life development in a multiethnic sample and the relation to late life cognition. The Journals of Gerontology Series B: Psychological Sciences and Social Sciences, 70(4), 519-531. doi:10.1093/geronb/gbt126

Meng, X., \& D'Arcy, C. (2012). Education and dementia in the context of the cognitive reserve hypothesis: a systematic review with meta-analyses and qualitative analyses. PLoS ONE, 7(6), e38268. 
Morley, J. E. (2011). Assessment of malnutrition in older persons: A focus on the mini nutritional assessment. The journal of nutrition, health \& aging, 15(2), 87-90. doi:10.1007/s12603-011-0018-4

Olivera, J., \& Tournier, I. (2016). Successful ageing and multi-dimensional poverty: the case of Peru. Ageing and Society, 36(08), 1690-1714.

Patel, R., Lawlor, D. A., Kramer, M. S., Davey Smith, G., Bogdanovich, N., Matush, L., \& Martin, R. M. (2011). Socioeconomic inequalities in height, leg length and trunk length among children aged 6.5 years and their parents from the Republic of Belarus: Evidence from the Promotion of Breastfeeding Intervention Trial (PROBIT). Annals of human biology, 38(5), 592-602.

Pelaez, M., Palloni, A., Albala, C., Alfonso, J., Ham-Chande, R., Hennis, A., Lebrao, M., LesnDiaz, E., Pantelides, E., Prats, O. (2005). SABE - Survey on Health, Well-being, and Aging in Latin America and the Caribbean, 2000. Pan American Health Organization, W. H. O. (PAHO/WHO), \& [Producers]. Washington, D.C.: Ann Arbor, MI: Interuniversity Consortium for Political and Social Research [Distributor].

Roman, S. P. (2004). Illiteracy and older adults: Individual and societal implications. Educational Gerontology, 30(2), 79-93.

Sousa, R. M., Ferri, C. P., Acosta, D., Albanese, E., Guerra, M., Huang, Y., . . . Pichardo, G. R. (2009). Contribution of chronic diseases to disability in elderly people in countries with low and middle incomes: a 10/66 Dementia Research Group population-based survey. The Lancet, 374(9704), 1821-1830.

Stern, Y. (2002). What is cognitive reserve? Theory and research application of the reserve concept. Journal of the International Neuropsychological Society, 8(03), 448-460. doi:10.1017/S1355617702813248

Suh, S. W., Han, J. W., Park, J. Y., Hong, J. W., Kim, K., Kim, T., . . Seo, J. (2016). Impacts of illiteracy on the risk of dementia: a global health perspective. Journal of Alzheimer's Disease, 53(2), 731-741.

Suominen, M., Muurinen, S., Routasalo, P., Soini, H., Suur-Uski, I., Peiponen, A., . . Pitkala, K. (2005). Malnutrition and associated factors among aged residents in all nursing homes in Helsinki. European Journal of Clinical Nutrition, 59(4), 578-583.

Van Dyk, K., \& Sano, M. (2007). The impact of nutrition on cognition in the elderly. Neurochemical research, 32(4-5), 893-904.

Vellas, B., Guigoz, Y., Garry, P. J., Nourhashemi, F., Bennahum, D., Lauque, S., \& Albarede, J.-L. (1999). The Mini Nutritional Assessment (MNA) and its use in grading the nutritional state of elderly patients. Nutrition, 15(2), 116-122.

Wachs, T. D. (1995). Relation of mild-to-moderate malnutrition to human development: correlation studies. The Journal of Nutrition, 125(8), $2245 \mathrm{~S}$.

Wehby, G. L., Castilla, E. E., \& Lopez-Camelo, J. (2010). The impact of altitude on infant health in South America. Economics \& Human Biology, 8(2), 197-211.

Whalley, L. J., Dick, F. D., \& McNeill, G. (2006). A life-course approach to the aetiology of late-onset dementias. The Lancet Neurology, 5(1), 87-96. doi:10.1016/S14744422(05)70286-6 


\section{TABLES AND FIGURES}

Table 1. Descriptive statistics of the sample

\begin{tabular}{|c|c|c|c|c|c|c|c|}
\hline \multirow{2}{*}{ Variable } & \multicolumn{2}{|c|}{ Men } & \multicolumn{2}{|c|}{ Women } & \multicolumn{2}{|c|}{ Total } & \multirow[t]{2}{*}{ mean differences } \\
\hline & mean & std dev & mean & std dev & mean & std dev & \\
\hline Total cognitive score (0-14) & 12.02 & 1.84 & 11.28 & 2.16 & 11.69 & 2.02 & $0.736 * * *$ \\
\hline Episodic memory score (0-6) & 5.06 & 1.11 & 5.06 & 1.18 & 5.06 & 1.14 & 0.01 \\
\hline Mental intactness score (0-8) & 6.95 & 1.17 & 6.22 & 1.47 & 6.63 & 1.36 & $0.730 * * *$ \\
\hline Age & 71.23 & 4.47 & 71.05 & 4.26 & 71.15 & 4.38 & 0.18 \\
\hline Years of education & 3.56 & 2.98 & 1.57 & 2.30 & 2.68 & 2.87 & $1.991 * * *$ \\
\hline No education $(0=$ no/ $1=y e s)$ & 0.10 & 0.30 & 0.47 & 0.50 & 0.26 & 0.44 & $-0.373 * * *$ \\
\hline Uncompleted primary educ $(0=$ no/ $1=y e s)$ & 0.61 & 0.49 & 0.42 & 0.49 & 0.53 & 0.50 & $0.189 * * *$ \\
\hline Completed primary educ or more $(0=$ no/ $1=y e s)$ & 0.29 & 0.45 & 0.11 & 0.31 & 0.21 & 0.41 & $0.185^{* * *}$ \\
\hline Arm span (in cm) & 162.13 & 9.15 & 148.44 & 7.70 & 156.02 & 10.91 & $13.690 * * *$ \\
\hline Mini Nutritional Assessment & 13.79 & 3.03 & 13.31 & 3.11 & 13.58 & 3.08 & $0.481 * * *$ \\
\hline Illiterate $(0=n o / 1=y e s)$ & 0.11 & 0.31 & 0.48 & 0.50 & 0.27 & 0.45 & $-0.367 * * *$ \\
\hline Urban (0=no/1=yes) & 0.33 & 0.47 & 0.44 & 0.50 & 0.38 & 0.49 & $-0.108 * * *$ \\
\hline Retired $(0=$ no/1=yes $)$ & 0.16 & 0.37 & 0.45 & 0.50 & 0.29 & 0.45 & $-0.296 * * *$ \\
\hline Mental disorders $(0=n o / 1=y e s)$ & 0.18 & 0.38 & 0.23 & 0.42 & 0.20 & 0.40 & $-0.046 * * *$ \\
\hline Smoking $(0=$ no/ $1=y e s)$ & 0.34 & 0.47 & 0.04 & 0.19 & 0.20 & 0.40 & $0.298 * * *$ \\
\hline Sample size & $\mathrm{n}=2167$ & & $\mathrm{n}=1743$ & & $\mathrm{n}=3910$ & & \\
\hline
\end{tabular}

Note: ${ }^{*} \mathrm{p}<0.1{ }^{* *} \mathrm{p}<0.05 * * * \mathrm{p}<0.01$. 
Table 2. Tobit models of later-life cognition

\begin{tabular}{|c|c|c|c|c|c|c|}
\hline \multirow[b]{2}{*}{ Variable } & \multicolumn{3}{|c|}{ Men } & \multicolumn{3}{|c|}{ Women } \\
\hline & $\begin{array}{l}\text { Episodic } \\
\text { memory }\end{array}$ & $\begin{array}{l}\text { Mental } \\
\text { intactness }\end{array}$ & Total & $\begin{array}{l}\text { Episodic } \\
\text { memory }\end{array}$ & $\begin{array}{l}\text { Mental } \\
\text { intactness }\end{array}$ & Total \\
\hline \multirow[t]{2}{*}{ Age } & $-0.0474 * * *$ & $-0.0489 * * *$ & $-0.0756 * * *$ & $-0.0631 * * *$ & $-0.0315 * * *$ & $-0.0665 * * *$ \\
\hline & $(0.0078)$ & $(0.0067)$ & $(0.0090)$ & $(0.0157)$ & $(0.0067)$ & $(0.0126)$ \\
\hline \multirow[t]{2}{*}{ Uncompl primary educ } & $0.2918 *$ & $0.6790 * * *$ & $0.7701^{* * *}$ & $0.5111^{* * *}$ & $1.2344 * * *$ & $1.4684 * * *$ \\
\hline & $(0.1558)$ & $(0.1376)$ & $(0.2178)$ & $(0.0964)$ & $(0.1053)$ & $(0.1405)$ \\
\hline \multirow[t]{2}{*}{ Primary educ or more } & $0.8100 * * *$ & $1.1253 * * *$ & $1.4681^{* * *}$ & $0.7714^{* * *}$ & $1.9835 * * *$ & $2.2261 * * *$ \\
\hline & $(0.1014)$ & $(0.1235)$ & $(0.1759)$ & $(0.1675)$ & $(0.1305)$ & $(0.1028)$ \\
\hline \multirow[t]{2}{*}{ Arm span (cm) } & 0.0032 & $0.0121^{*}$ & $0.0128 * *$ & 0.0057 & $0.0059 *$ & $0.0111^{*}$ \\
\hline & $(0.0061)$ & $(0.0067)$ & $(0.0051)$ & $(0.0077)$ & $(0.0035)$ & $(0.0065)$ \\
\hline \multirow[t]{2}{*}{ Mini Nutritional Assessment } & $0.0219 *$ & $0.0758 * * *$ & $0.0815 * * *$ & $0.0863 * * *$ & $0.0952 * * *$ & $0.1464 * * *$ \\
\hline & $(0.0127)$ & $(0.0095)$ & $(0.0152)$ & $(0.0139)$ & $(0.0103)$ & $(0.0162)$ \\
\hline \multirow[t]{2}{*}{ Urban } & 0.0625 & 0.0386 & 0.0819 & -0.0035 & $0.1879 * *$ & $0.1947 * *$ \\
\hline & $(0.0994)$ & $(0.0859)$ & $(0.1252)$ & $(0.1136)$ & $(0.0904)$ & $(0.0876)$ \\
\hline \multirow[t]{2}{*}{ Retired } & $-0.3975 * * *$ & $-0.2667 * *$ & $-0.5136 * * *$ & -0.1283 & $-0.2093 * * *$ & $-0.2700 * * *$ \\
\hline & $(0.1013)$ & $(0.1150)$ & $(0.1276)$ & $(0.0894)$ & $(0.0752)$ & $(0.0745)$ \\
\hline \multirow[t]{2}{*}{ Mental disorders } & $-0.3292 * * *$ & $-0.2782 * *$ & $-0.4654 * * *$ & $-0.2974 * * *$ & -0.0427 & $-0.2297 * *$ \\
\hline & $(0.0898)$ & $(0.1205)$ & $(0.1063)$ & $(0.0813)$ & $(0.0836)$ & $(0.0943)$ \\
\hline \multirow[t]{2}{*}{ Smoking } & 0.0008 & -0.1146 & -0.0799 & 0.0112 & 0.1131 & 0.1621 \\
\hline & $(0.1065)$ & $(0.0957)$ & $(0.1162)$ & $(0.2522)$ & $(0.2450)$ & $(0.3572)$ \\
\hline \multirow[t]{2}{*}{ Constant } & $8.1710 * * *$ & $6.6752 * * *$ & $13.4297 * * *$ & $8.4342^{* * *}$ & $5.5417 * * *$ & $11.6903 * * *$ \\
\hline & $(0.7023)$ & (1.1526) & $(0.8287)$ & $(2.0086)$ & $(0.5974)$ & $(1.4781)$ \\
\hline Observations & 2167 & 2167 & 2167 & 1743 & 1743 & 1743 \\
\hline Pseudo $\mathrm{R}^{2}$ & 0.0304 & 0.0436 & 0.0432 & 0.0387 & 0.0901 & 0.0720 \\
\hline
\end{tabular}

Note: ${ }^{*} p<0.1 .{ }^{* *} p<0.05 .{ }^{* * *} p<0.01$. All models include dummies of departments. Robust standard errors clustered by department are reported in parentheses. The reference value for the dummy variables of education is 'no education'. 
Table 3. Tobit models of later-life cognition with interactions of arm span, MNA and education

\begin{tabular}{|c|c|c|c|c|c|c|}
\hline \multirow[b]{2}{*}{ Variable } & \multicolumn{3}{|c|}{ Men } & \multicolumn{3}{|c|}{ Women } \\
\hline & $\begin{array}{l}\text { Episodic } \\
\text { memory }\end{array}$ & $\begin{array}{l}\text { Mental } \\
\text { intactness }\end{array}$ & Total & $\begin{array}{l}\text { Episodic } \\
\text { memory }\end{array}$ & $\begin{array}{l}\text { Mental } \\
\text { intactness }\end{array}$ & Total \\
\hline Age & $\begin{array}{l}-0.0478 * * * \\
(0.0082)\end{array}$ & $\begin{array}{l}-0.0488 * * * \\
(0.0069)\end{array}$ & $\begin{array}{l}-0.0755 * * * \\
(0.0093)\end{array}$ & $\begin{array}{l}-0.0635 * * * \\
(0.0156)\end{array}$ & $\begin{array}{l}-0.0316 * * * \\
(0.0068)\end{array}$ & $\begin{array}{l}-0.0669 * * * \\
(0.0123)\end{array}$ \\
\hline Uncompleted primary education & $\begin{array}{l}-0.0548 \\
(1.6604)\end{array}$ & $\begin{array}{l}-0.0718 \\
(3.6359)\end{array}$ & $\begin{array}{l}0.4173 \\
(3.9406)\end{array}$ & $\begin{array}{l}1.7652 \\
(1.5922)\end{array}$ & $\begin{array}{l}1.5341 \\
(2.0423)\end{array}$ & $\begin{array}{l}3.2596 \\
(2.2047)\end{array}$ \\
\hline Primary education or more & $\begin{array}{l}4.5979 * * \\
(2.0956)\end{array}$ & $\begin{array}{l}-0.5058 \\
(3.5300)\end{array}$ & $\begin{array}{l}3.8263 \\
(3.9397)\end{array}$ & $\begin{array}{l}-2.9057 \\
(4.8474)\end{array}$ & $\begin{array}{l}3.5179 \\
(3.3769)\end{array}$ & $\begin{array}{l}1.3303 \\
(4.7116)\end{array}$ \\
\hline Arm span $(\mathrm{cm})$ & $\begin{array}{l}0.0075 \\
(0.0062)\end{array}$ & $\begin{array}{l}0.0065 \\
(0.0176)\end{array}$ & $\begin{array}{l}0.0132 \\
(0.0161)\end{array}$ & $\begin{array}{l}0.0070 \\
(0.0087)\end{array}$ & $\begin{array}{l}0.0070 \\
(0.0050)\end{array}$ & $\begin{array}{l}0.0142 \\
(0.0091)\end{array}$ \\
\hline Uncomp primary educ*Arm span & $\begin{array}{l}0.0011 \\
(0.0082)\end{array}$ & $\begin{array}{l}0.0052 \\
(0.0198)\end{array}$ & $\begin{array}{l}0.0034 \\
(0.0202)\end{array}$ & $\begin{array}{l}-0.0069 \\
(0.0111)\end{array}$ & $\begin{array}{l}-0.0007 \\
(0.0122)\end{array}$ & $\begin{array}{l}-0.0081 \\
(0.0133)\end{array}$ \\
\hline Primary educ or more*Arm span & $\begin{array}{l}-0.0247^{* *} \\
(0.0104)\end{array}$ & $\begin{array}{l}0.0114 \\
(0.0189)\end{array}$ & $\begin{array}{l}-0.0119 \\
(0.0198)\end{array}$ & $\begin{array}{l}0.0238 \\
(0.0296)\end{array}$ & $\begin{array}{l}-0.0126 \\
(0.0229)\end{array}$ & $\begin{array}{l}0.0070 \\
(0.0298)\end{array}$ \\
\hline Mini Nutritional Assessment (MNA) & $\begin{array}{l}0.0090 \\
(0.0421)\end{array}$ & $\begin{array}{l}0.0849 * \\
(0.0461)\end{array}$ & $\begin{array}{l}0.0998 \\
(0.0662)\end{array}$ & $\begin{array}{l}0.0926 * * * \\
(0.0182)\end{array}$ & $\begin{array}{l}0.0995 * * * \\
(0.0145)\end{array}$ & $\begin{array}{l}0.1664 * * * \\
(0.0223)\end{array}$ \\
\hline Uncomp primary educ*MNA & $\begin{array}{l}0.0127 \\
(0.0412)\end{array}$ & $\begin{array}{l}-0.0073 \\
(0.0457)\end{array}$ & $\begin{array}{l}-0.0155 \\
(0.0616)\end{array}$ & $\begin{array}{l}-0.0175 \\
(0.0236)\end{array}$ & $\begin{array}{l}-0.0147 \\
(0.0241)\end{array}$ & $\begin{array}{l}-0.0446 \\
(0.0346)\end{array}$ \\
\hline Primary educ or more*MNA & $\begin{array}{l}0.0178 \\
(0.0466)\end{array}$ & $\begin{array}{l}-0.0160 \\
(0.0511)\end{array}$ & $\begin{array}{l}-0.0304 \\
(0.0709)\end{array}$ & $\begin{array}{l}0.0053 \\
(0.0626)\end{array}$ & $\begin{array}{l}0.0247 \\
(0.0480)\end{array}$ & $\begin{array}{l}-0.0141 \\
(0.0737)\end{array}$ \\
\hline Urban & $\begin{array}{l}0.0566 \\
(0.0971)\end{array}$ & $\begin{array}{l}0.0426 \\
(0.0848)\end{array}$ & $\begin{array}{l}0.0831 \\
(0.1251)\end{array}$ & $\begin{array}{l}0.0018 \\
(0.1170)\end{array}$ & $\begin{array}{l}0.1879 * * \\
(0.0929)\end{array}$ & $\begin{array}{l}0.1977 * * \\
(0.0913)\end{array}$ \\
\hline Retired & $\begin{array}{l}-0.3980 * * * \\
(0.0992)\end{array}$ & $\begin{array}{l}-0.2660 * * \\
(0.1117)\end{array}$ & $\begin{array}{l}-0.5132 * * * \\
(0.1271)\end{array}$ & $\begin{array}{l}-0.1222 \\
(0.0872)\end{array}$ & $\begin{array}{l}-0.2100 * * * \\
(0.0762)\end{array}$ & $\begin{array}{l}-0.2652 * * * \\
(0.0747)\end{array}$ \\
\hline Mental disorders & $\begin{array}{l}-0.3232 * * * \\
(0.0928)\end{array}$ & $\begin{array}{l}-0.2785 * * \\
(0.1217)\end{array}$ & $\begin{array}{l}-0.4593 * * * \\
(0.1087)\end{array}$ & $\begin{array}{l}-0.2974 * * * \\
(0.0791)\end{array}$ & $\begin{array}{l}-0.0396 \\
(0.0835)\end{array}$ & $\begin{array}{l}-0.2280 * * \\
(0.0926)\end{array}$ \\
\hline Smoking & $\begin{array}{l}0.0007 \\
(0.1028)\end{array}$ & $\begin{array}{l}-0.1131 \\
(0.0967)\end{array}$ & $\begin{array}{l}-0.0783 \\
(0.1142)\end{array}$ & $\begin{array}{l}0.0147 \\
(0.2496)\end{array}$ & $\begin{array}{l}0.1105 \\
(0.2433)\end{array}$ & $\begin{array}{l}0.1630 \\
(0.3567)\end{array}$ \\
\hline Constant & $\begin{array}{l}7.6747 * * * \\
(0.9487)\end{array}$ & $\begin{array}{l}7.4553 * * \\
(3.5177)\end{array}$ & $\begin{array}{l}13.1253 * * * \\
(3.4776)\end{array}$ & $\begin{array}{l}8.1800 * * * \\
(2.0129)\end{array}$ & $\begin{array}{l}5.3298 * * * \\
(0.9314)\end{array}$ & $\begin{array}{l}11.0066^{* * * *} \\
(1.9220)\end{array}$ \\
\hline $\begin{array}{l}\text { Observations } \\
\text { Pseudo } \mathrm{R}^{2}\end{array}$ & $\begin{array}{l}2167 \\
0.0312\end{array}$ & $\begin{array}{l}2167 \\
0.0437\end{array}$ & $\begin{array}{l}2167 \\
0.0434\end{array}$ & $\begin{array}{l}1743 \\
0.0390\end{array}$ & $\begin{array}{l}1743 \\
0.0903\end{array}$ & $\begin{array}{l}1743 \\
0.0723\end{array}$ \\
\hline
\end{tabular}

Note: $* \mathrm{p}<0.1^{* *} \mathrm{p}<0.05^{* * *} \mathrm{p}<0.01$. All models include dummies of departments. Robust standard errors clustered by department are reported in parentheses. The reference value for the dummy variables of education is 'no education'. 
Table 4. Tobit models for later-life cognition in a sample of individuals without education

\begin{tabular}{|c|c|c|c|c|c|c|}
\hline \multirow{2}{*}{ Variable } & \multicolumn{3}{|c|}{ Men } & \multicolumn{3}{|c|}{ Women } \\
\hline & Episodic memory & Mental intactness & Total & Episodic memory & Mental intactness & Total \\
\hline \multirow[t]{2}{*}{ Age } & -0.0066 & $-0.0718 * * *$ & $-0.0706 * *$ & $-0.0390 * *$ & $-0.0279 * * *$ & $-0.0545 * * *$ \\
\hline & $(0.0349)$ & $(0.0239)$ & $(0.0323)$ & $(0.0175)$ & $(0.0070)$ & $(0.0111)$ \\
\hline \multirow[t]{2}{*}{ Arm span (cm) } & $0.0141^{*}$ & 0.0055 & 0.0169 & 0.0078 & $0.0100 * * *$ & $0.0172 * *$ \\
\hline & $(0.0084)$ & $(0.0143)$ & $(0.0149)$ & $(0.0087)$ & $(0.0035)$ & $(0.0078)$ \\
\hline \multirow{2}{*}{$\begin{array}{l}\text { Mini Nutritional } \\
\text { Assessment }\end{array}$} & -0.0464 & $0.1147^{* *}$ & 0.0904 & $0.0898 * * *$ & $0.0943 * * *$ & $0.1596 * * *$ \\
\hline & $(0.0369)$ & $(0.0453)$ & $(0.0588)$ & $(0.0208)$ & $(0.0111)$ & $(0.0197)$ \\
\hline \multirow[t]{2}{*}{ Illiterate } & $-0.5803 * * *$ & $-0.9009 * * *$ & $-1.2211^{* * *}$ & $-0.6954 * *$ & -0.6949 & $-1.0394 *$ \\
\hline & $(0.2075)$ & $(0.1977)$ & $(0.2154)$ & $(0.3096)$ & $(0.4477)$ & $(0.5705)$ \\
\hline \multirow[t]{2}{*}{ Urban } & -0.0777 & $-0.3798 *$ & -0.3924 & -0.0078 & 0.0834 & 0.0819 \\
\hline & $(0.3531)$ & $(0.1934)$ & $(0.3260)$ & $(0.0927)$ & $(0.1542)$ & $(0.1699)$ \\
\hline \multirow[t]{2}{*}{ Retired } & -0.6507 & 0.0350 & -0.4722 & $-0.1736 * *$ & $-0.1855 * * *$ & $-0.2356 * * *$ \\
\hline & $(0.4188)$ & $(0.4170)$ & $(0.6367)$ & $(0.0834)$ & $(0.0618)$ & $(0.0784)$ \\
\hline \multirow[t]{2}{*}{ Mental disorders } & 0.1642 & $0.4435 * * *$ & $0.4149 *$ & $-0.4584 * * *$ & -0.1500 & $-0.4509 * * *$ \\
\hline & $(0.3291)$ & $(0.1395)$ & $(0.2293)$ & $(0.1566)$ & $(0.0931)$ & $(0.1584)$ \\
\hline \multirow[t]{2}{*}{ Smoking } & -0.4257 & -0.5236 & -0.7003 & 0.1693 & 0.1733 & 0.2959 \\
\hline & $(0.4183)$ & $(0.3206)$ & $(0.5237)$ & $(0.2290)$ & $(0.2597)$ & $(0.2835)$ \\
\hline \multirow[t]{2}{*}{ Constant } & 4.1812 & $9.2685 * *$ & $12.4324 * * *$ & $7.1416 * * *$ & $5.2010 * * *$ & $10.6036 * * *$ \\
\hline & $(2.5844)$ & (3.6279) & (3.3924) & $(2.2584)$ & $(0.7864)$ & (1.7069) \\
\hline Observations & 189 & 189 & 189 & 802 & 802 & 802 \\
\hline Pseudo R ${ }^{2}$ & 0.0448 & 0.0961 & 0.0747 & 0.0353 & 0.0400 & 0.0426 \\
\hline
\end{tabular}

